\title{
Preparation of activated carbon from coconut husk: Optimization study on removal of 2,4,6-trichlorophenol using response surface methodology
}

\author{
I.A.W. Tan, A.L. Ahmad, B.H. Hameed* \\ School of Chemical Engineering, Universiti Sains Malaysia, Engineering Campus, 14300 Nibong Tebal, Penang, Malaysia \\ Received 17 July 2007; received in revised form 30 August 2007; accepted 3 September 2007 \\ Available online 6 September 2007
}

\begin{abstract}
Activated carbon was prepared from coconut husk using physicochemical activation method which consisted of potassium hydroxide (KOH) treatment and carbon dioxide $\left(\mathrm{CO}_{2}\right)$ gasification. The effects of three preparation variables $\left(\mathrm{CO}_{2}\right.$ activation temperature, $\mathrm{CO}$ activation time and $\mathrm{KOH}$ :char impregnation ratio) on the 2,4,6-trichlorophenol (2,4,6-TCP) uptake and activated carbon yield were investigated. Based on the central composite design, two quadratic models were developed to correlate the preparation variables to the two responses. From the analysis of variance (ANOVA), the most influential factor on each experimental design response was identified. The activated carbon preparation conditions were optimized by maximizing both the 2,4,6-TCP uptake and activated carbon yield. The predicted 2,4,6-TCP uptake and carbon yield from the models agreed satisfactorily with the experimental values. The optimum conditions for preparing activated carbon from coconut husk for adsorption of 2,4,6-TCP were found as follow: $\mathrm{CO}_{2}$ activation temperature of $750{ }^{\circ} \mathrm{C}, \mathrm{CO}_{2}$ activation time of $2.29 \mathrm{~h}$ and $\mathrm{KOH}$ :char impregnation ratio of 2.91 , which resulted in $191.73 \mathrm{mg} / \mathrm{g}$ of 2,4,6-TCP uptake and $20.16 \%$ of activated carbon yield.
\end{abstract}

(C) 2007 Elsevier B.V. All rights reserved.

Keywords: Coconut husk activated carbon; Adsorption; 2,4,6-Trichlorophenol; Central composite design; Optimization

\section{Introduction}

Chlorophenols are a group of chemicals in which chlorines have been added to phenol. Chlorophenols have been prescribed as priority pollutants by the US Environmental Protection Agency (EPA) due to their toxicity and adverse effects upon human [1]. They are the most common organic pollutants used widely in agriculture, industry and public health. The most important chlorophenol sources are wastewaters from pesticide, paint, solvent, pharmaceutics, paper and pulp industries as well as water disinfecting process [2]. Chlorophenols are weak acids and permeate human skin by in vitro and are readily absorbed by gastro-intestinal tract. The acute toxicity of chlorophenols includes increased respiratory rate, vomiting and nausea [3]. Chlorophenols also create complicated problems to water bodies such as bad odour and taste in drinking water, death of aquatic life, inhibition of normal activities of microbial population in wastewater treatment plant, etc. Therefore, the efficiency of tra-

\footnotetext{
* Corresponding author. Tel.: +604 599 6422; fax: +604 5941013

E-mail address: chbassim@eng.usm.my (B.H. Hameed).
}

ditional biological treatment method is not satisfying due to chlorophenol's structural stabilization and toxicity [2]. Besides, they also display a pronounced undesirable effect in potable water at concentration as low as $0.1 \mathrm{mg} / 1$ [3]. As one type of the most hazardous materials, they are carcinogenic, mutagenic and resistant to biodegradation, and thus have to be decomposed before discharging into receiving waters, in order to avoid the biomagnified toxicity to aquatic flora and fauna through various food chains [4].

Adsorption on activated carbon has been found to be superior compared to other chemical and physical methods for wastewater treatment in terms of its capability for efficiently adsorbing a broad range of pollutants, fast adsorption kinetics and its simplicity of design. However, commercially available activated carbons are still expensive due to the use of non-renewable and relatively high-cost starting material such as coal, which is unjustified in pollution control applications [5,6]. Therefore, in recent years, many researchers have tried to produce activated carbons for removal of various pollutants using renewable and cheaper precursors which were mainly industrial and agricultural byproducts, such as coconut shell [3], waste apricot [7], sugar beet bagasse [8], molasses [9], rubberwood sawdust [10], rice straw 